\title{
Impact of prior anthracycline or taxane use on eribulin effectiveness as first-line treatment for metastatic breast cancer: results from two phase 2, multicenter, single-arm studies
}

Joyce O'Shaughnessy ${ }^{1 *}$, Kristi Mclntyre ${ }^{2}$, Lee Schwartzberg ${ }^{3}$, Sharon Wilks ${ }^{4}$, Shannon Puhalla ${ }^{5}$, Erhan Berrak ${ }^{6}$, James Song ${ }^{6}$ and Linda Vahdat ${ }^{7}$

\begin{abstract}
Eribulin mesylate has efficacy in patients who have received $\geq 2$ prior chemotherapies for metastatic breast cancer (MBC) including an anthracycline and taxane. Phase 2 trials showed clinical activity and acceptable tolerability of first-line eribulin (HER2- MBC; Study 206) and eribulin plus trastuzumab (HER2+ MBC; Study 208). Prespecified analyses evaluated efficacy by prior anthracycline and/or taxane use. Patients received eribulin mesylate $\left(1.4 \mathrm{mg} / \mathrm{m}^{2}\right.$ IV; Days 1 and 8) and, in Study 208, trastuzumab (8 mg/kg IV/Cycle 1, then 6 mg/kg; Day 1) in 21-day cycles. Endpoints included objective response rate (ORR), progression-free survival (PFS), and tolerability. In Study 206 ( $N=56$ ), $48 \%$ of patients had received prior anthracycline, $46 \%$ prior taxane, $36 \%$ prior anthracycline and taxane, and $41 \%$ were chemotherapy-naïve. In Study $208(N=52)$, these percentages were 21, 44, 17, and $52 \%$, respectively. In Study 206, ORR and median PFS were similar for anthracycline-pretreated (25.9\%, 5.8 months), taxane-pretreated (26.9\%, 5.8 months), anthracycline- and taxane-pretreated (25.0\%, 6.7 months), and anthracycline/taxane-naïve patients (30.4 \%, 7.6 months). In Study 208, ORR/median PFS were 63.6\%/6.7 months among anthracycline-pretreated patients, $56.5 \% / 6.8$ months among taxane-pretreated patients, $55.6 \% / 5.9$ months among anthracycline- and taxanepretreated patients, and $81.5 \% / 13.1$ months among anthracycline/taxane-naïve patients. Tolerability was generally similar among subgroups. In these studies, first-line eribulin in HER2- MBC and eribulin/trastuzumab in HER2+ MBC was effective with acceptable tolerability, regardless of prior anthracycline/taxane treatment. Prior chemotherapy was associated with lower ORR and shorter PFS with eribulin/trastuzumab in HER2+ MBC but not with eribulin in HER2- MBC.
\end{abstract}

Keywords: Eribulin, Metastatic breast cancer, Prior chemotherapy, Objective response rate, Progression-free survival, Tolerability

\section{Background}

In the US, approximately 5-10\% of women diagnosed with breast cancer (BC) have de novo metastatic disease and have an estimated 5-year survival rate of $24.3 \%$

\footnotetext{
${ }^{*}$ Correspondence: joyce.oshaughnessy@usoncology.com

${ }^{1}$ Texas Oncology-Baylor Charles A. Sammons Cancer Center, US

Oncology, 3410 Worth Street, Ste 400, Dallas, TX 75246, USA

Full list of author information is available at the end of the article
}

(National Cancer Institute 2014; American Cancer Society 2014). In addition, approximately $30 \%$ of patients with stage I to III BC at diagnosis will subsequently develop metastatic disease (O'Shaughnessy 2005). Treatment selection for metastatic breast cancer $(\mathrm{MBC})$ is guided by several factors, including patients' choices, hormone receptor (estrogen receptor and progesterone receptor) expression, human epidermal growth factor 
receptor 2 (HER2) expression, site and burden of metastases, disease-related symptoms, prior treatment history, toxicity, comorbid conditions, patient age, and menopausal status, amongst others (National Comprehensive Cancer Network 2015; Partridge et al. 2014).

The overall rate of $\mathrm{BC}$ that overexpresses the transmembrane tyrosine kinase receptor, HER2, is $22.2 \%$ as was demonstrated in a recent survey of 107 published studies involving 39,730 patients (Ross et al. 2009). Preferred single agents for $\mathrm{MBC}$ chemotherapy according to NCCN guidelines include anthracyclines, taxanes, antimetabolites (e.g., capecitabine and gemcitabine), and other microtubule disrupting agents (e.g., vinorelbine and eribulin) (National Comprehensive Cancer Network 2015). Current guidelines recommend sequential singleagent chemotherapy (in most cases) for HER2-negative (HER2-) MBC that is hormone receptor-negative or endocrine-resistant; however, there is not a single specific preferred chemotherapy agent or regimen (National Comprehensive Cancer Network 2015; Partridge et al. 2014). For women with HER2-positive (HER2+) metastatic disease, trastuzumab, a humanized monoclonal antibody directed against the extracellular domain of HER2 (Valabrega et al. 2007), combined with recently approved pertuzumab and a taxane (docetaxel or paclitaxel) are recommended as first-line therapy (National Comprehensive Cancer Network 2015; Giordano et al. 2014).

Eribulin is a non-taxane microtubule inhibitor that is a structurally modified synthetic analog of halichondrin B (Jordan et al. 2005; Okouneva et al. 2008; Smith et al. 2010; Jordan and Kamath 2007). Eribulin has a unique mode of cytotoxic action that is distinct from those of other tubulin-targeting agents; it binds and inhibits only the growing + ends, inhibiting the microtubule growth phase without affecting the shortening phase and causes tubulin sequestration into non-productive aggregates. This novel tubulin-directed mechanism may explain eribulin's observed non-cross-resistant antitumor activity following taxane therapy (Jordan et al. 2005; Okouneva et al. 2008; Smith et al. 2010; Jordan and Kamath 2007; Jain and Cigler 2012).

In women with $\mathrm{MBC}$ who had previously received at least 2 chemotherapeutic regimens (including an anthracycline and a taxane) for metastatic disease, eribulin has demonstrated antitumor activity and improved overall survival (Vahdat et al. 2009; Cortes et al. 2010; Aogi et al. 2012; Cortes et al. 2011; Halaven ${ }^{\circledR}$ 2014). Approval by the United States (US) Food and Drug Administration for eribulin in this setting was based on the results from the phase 3 EMBRACE study, where single-agent eribulin significantly improved overall survival (OS) in patients with $\mathrm{MBC}$ compared with treatment of physician's choice
(Cortes et al. 2011). A more recent phase 3 study, which compared eribulin and capecitabine as first-, second-, or third-line therapy for MBC in women who had previously received an anthracycline and a taxane, found no significant difference in OS between the 2 treatments [hazard ratio 0.88 (95\% CI 0.77, 1.00); $\mathrm{p}=0.056$ ]; however, for eribulin the median OS (15.9 months), median PFS (4.1 months), and objective response rate (11\%) were comparable to those achieved with eribulin in the EMBRACE trial (13.1, 3.7 months, and $12 \%$, respectively) (Cortes et al. 2011; Kaufman et al. 2015).

Due to its antitumor activity in the challenging setting of late-line treatment, infusion schedule $\left(1.4 \mathrm{mg} / \mathrm{m}^{2}\right.$ IV over 2-5 min on Days 1 and 8 of a 21-day cycle), and lack of premedication requirement to prevent hypersensitivity, assessment of eribulin in the first-line setting for women with $\mathrm{MBC}$ was of clinical interest (Cortes et al. 2011; Halaven ${ }^{\circledR}$ 2014). Results from two, single-arm, multicenter, phase 2 trials, Study 206 (eribulin monotherapy in HER2- MBC) and Study 208 (combination eribulin plus trastuzumab in HER2+ MBC), as first-line treatment in patients with locally recurrent $\mathrm{BC}$ or $\mathrm{MBC}$ have been published (McIntyre et al. 2014; Wilks et al. 2014). In Study $206(\mathrm{~N}=56)$, the objective response rate (ORR) with single-agent eribulin was $29 \%$, median duration of response (DOR) was 5.8 months, and median progression-free survival (PFS) was 6.8 months (McIntyre et al. 2014). In Study $208(\mathrm{~N}=52)$, ORR with eribulin/trastuzumab was $71.2 \%$, median DOR was 11.1 months, and median PFS was 11.6 months (Wilks et al. 2014). Because many patients receive an anthracycline as adjuvant or neoadjuvant (neo/adjuvant therapy), we conducted a prespecified analysis of both trials to examine efficacy of these regimens based on prior anthracycline and/or taxane pretreatment.

\section{Methods}

\section{Study design}

Complete trial methodology for the 206 and 208 studies have been previously published (McIntyre et al. 2014; Wilks et al. 2014). Both were multicenter, phase 2, open-label trials that assessed eribulin as first-line treatment in patients with HER2- locally recurrent $\mathrm{BC}$ or MBC not previously treated with chemotherapy in the metastatic setting (Study 206) or eribulin combined with trastuzumab treatment in patients with HER2+ locally recurrent BC or MBC (Study 208). Both studies were conducted in accordance with the Declaration of Helsinki, and the protocols and informed consent forms were approved by institutional review boards. All patients for both studies provided written informed consent before undergoing any study-related procedures. 


\section{Endpoints}

Prespecified analyses included evaluation of the primary and secondary endpoints of ORR and PFS, respectively, according to prior neo/adjuvant anthracycline or taxane pretreatment. For both trials, the primary efficacy variable was ORR, defined as the proportion of patients who achieved an overall best response of complete response (CR) or a partial response (PR). PFS was measured from the start of treatment until disease progression or death from any cause. The censoring rules for PFS were according to FDA guidance in 2007. Tumor assessments were performed every 6 weeks in the first 6 cycles and every 12 weeks thereafter using RECIST v1.1.

\section{Safety/tolerability}

Safety evaluations at baseline and subsequent visits included adverse events (AEs), clinical laboratory tests, physical examination, vital signs, and electrocardiogram assessments. Treatment-emergent AEs (TEAEs) were defined as AEs that started or worsened after the first dose of study treatment.

\section{Statistical analysis}

The statistical methods have been published with the primary analyses for Studies 206 and 208 (McIntyre et al. 2014; Wilks et al. 2014). Efficacy analyses were based primarily on the full analysis set (FAS), which included all patients who received $\geq 1$ dose(s) of study treatment. The safety analysis set included all patients who received $\geq 1$ dose(s) of eribulin and had $\geq 1$ postbaseline safety evaluation. All efficacy endpoints were summarized descriptively. Kaplan-Meier method was used to estimate the time to event variables (e.g., PFS). Greenwood method was used to construct $95 \%$ confidence interval $(95 \% \mathrm{CI})$ for the median. Exact method was used to construct $95 \%$ CI for rate variables (e.g., ORR). Statistical analyses and summaries were performed using SAS for Windows v. 9.3 .

\section{Results}

\section{Baseline characteristics and demographics}

In Study 206 (single-agent eribulin in HER2- MBC), 56 female patients were enrolled, of which, $48 \%(n=27)$ had received prior anthracycline treatment and $46 \%$ $(\mathrm{n}=26)$ had received prior taxane treatment, $36 \%$ $(\mathrm{n}=20)$ had received both anthracycline and taxane, and $41 \%(\mathrm{n}=23)$ were anthracycline- and taxanenaïve (Table 1). For Study 206 patients, mean age was 57.0 years. Median relative delivered dose intensity for eribulin treatment ranged from 98.7 to $98.9 \%$ across the anthracycline- and/or taxane-pretreated subgroups. Median treatment duration was 19.1 weeks in anthracycline-pretreated patients, 16.1 weeks in taxane-pretreated patients, 21.4 weeks in anthracyclineand taxane-pretreated patients, and 27.0 weeks anthracycline- and taxane-naïve patients.

Fifty-two patients were enrolled in Study 208 (eribulin plus trastuzumab in HER2+ MBC), of which, $21 \%$ $(\mathrm{n}=11)$ had received prior anthracycline treatment, $44 \%(\mathrm{n}=23)$ prior taxane treatment, $17 \%(\mathrm{n}=9)$ had received both anthracycline and taxane, and $52 \%$ $(\mathrm{n}=27)$ were anthracycline- and taxane-naïve (Table 2). Mean age was 58.7 years and median delivered relative dose intensity for eribulin treatment across all anthracycline- and taxane-pretreatment subgroups ranged from 93.8 to $98.5 \%$. Median treatment duration was 28.0 weeks in anthracycline-pretreated patients, 28.1 weeks in taxane-pretreated patients, 21.4 weeks in anthracycline- and taxane-pretreated patients, and 37.3 weeks in anthracycline- and taxane-naïve patients.

Data regarding eribulin administration for Studies 206 and 208 including duration, relative dose intensity, and average treatment day dose can found in Additional file 1: Table S1.

\section{Efficacy outcomes}

In Study 206, ORR and median PFS were $25.9 \%$ and 5.8 months among patients who had received prior anthracycline, $26.9 \%$ and 5.8 months among patients who had received prior taxane, $25.0 \%$ and 6.7 months among patients who had received both anthracycline and taxane, and $30.4 \%$ and 7.6 months among patients who were anthracycline- and taxane-naïve (Table 3; Fig. 1a).

In Study 208, ORR and median PFS were $63.6 \%$ and 6.7 months among anthracycline-pretreated patients, $56.5 \%$ and 6.8 months among taxane-pretreated patients, $55.6 \%$ and 5.9 months among anthracycline- and taxane-pretreated patients, and $81.5 \%$ and 13.1 months among anthracycline- and taxane-naïve patients (Table 3; Fig. 1b).

\section{Safety/tolerability}

In Study 206, rates of serious TEAEs were similar in patients who had received prior anthracycline (29.6\%) and in those who had received prior taxane treatment (26.9\%); rates were $20.0 \%$ in patients who had received both anthracycline and taxane, and $26.1 \%$ in patients who were anthracycline- and taxane-naive. In Study 208, rates of serious TEAEs were $27.3 \%$ in patients who had received prior anthracycline, $30.4 \%$ in patients who had received prior taxane treatment, $33.3 \%$ in patients who had received both anthracycline and taxane, and $29.6 \%$ in patients who were anthracycline- and taxane-naive.

In Study 206, dose modifications due to AEs occurred at a similar rate in patients who had received prior anthracycline $(66.7 \%)$, prior taxane $(65.4 \%)$, or both 
Table 1 Study 206 (Single-Agent Eribulin in HER2- MBC): demographics and baseline characteristics

\begin{tabular}{|c|c|c|c|c|}
\hline & $\begin{array}{l}\text { With prior anthracycline } \\
(n=27)\end{array}$ & $\begin{array}{l}\text { With prior taxane } \\
(n=26)\end{array}$ & $\begin{array}{l}\text { With prior anthracycline } \\
\text { and taxane }(n=20)\end{array}$ & $\begin{array}{l}\text { Without prior anthracycline } \\
\text { or taxane }(n=23)\end{array}$ \\
\hline Female, n (\%) & $27(100)$ & $26(100)$ & $20(100)$ & $23(100)$ \\
\hline \multicolumn{5}{|l|}{ Age (years) } \\
\hline Mean (SD) & $55(10)$ & $55(11)$ & $55(11)$ & $61(11)$ \\
\hline \multicolumn{5}{|c|}{ Age group, n (\%) } \\
\hline$<50$ years & $9(33)$ & $9(35)$ & $7(35)$ & $3(13)$ \\
\hline $50-65$ years & $13(48)$ & $11(42)$ & $8(40)$ & $10(43)$ \\
\hline$>65$ years & $5(19)$ & $6(23)$ & $5(25)$ & $10(43)$ \\
\hline \multicolumn{5}{|c|}{ Age at diagnosis (years) } \\
\hline Mean (SD) & $49(10)$ & $52(11)$ & $52(10)$ & $57(11)$ \\
\hline \multicolumn{5}{|c|}{ Estrogen receptor (ER) status, n (\%) } \\
\hline+ & $17(63)$ & $13(50)$ & $11(55)$ & $22(96)$ \\
\hline- & $10(37)$ & $13(50)$ & $9(45)$ & $1(4)$ \\
\hline \multicolumn{5}{|c|}{ Progesterone receptor (PR) status, n (\%) } \\
\hline+ & $18(67)$ & $13(50)$ & $12(60)$ & $19(83)$ \\
\hline- & $9(33)$ & $13(50)$ & $8(40)$ & $4(17)$ \\
\hline \multicolumn{5}{|c|}{ HER2 status, n (\%) } \\
\hline+ & 0 & 0 & 0 & 0 \\
\hline - & $27(100)$ & $26(100)$ & $20(100)$ & $23(100)$ \\
\hline
\end{tabular}

SD standard deviation

Table 2 Study 208 (Eribulin + Trastuzumab in HER2 + MBC): demographics and baseline characteristics

\begin{tabular}{|c|c|c|c|c|}
\hline & $\begin{array}{l}\text { With prior anthracycline } \\
(\mathrm{n}=11)\end{array}$ & $\begin{array}{l}\text { With prior taxane } \\
(n=23)\end{array}$ & $\begin{array}{l}\text { With prior anthracycline } \\
\text { and taxane }(n=9)\end{array}$ & $\begin{array}{l}\text { Without prior anthracycline } \\
\text { or taxane }(n=27)\end{array}$ \\
\hline \multicolumn{5}{|l|}{ Sex, n (\%) } \\
\hline Female & $11(100)$ & $23(100)$ & $9(100)$ & $26(96)$ \\
\hline Male & 0 & 0 & 0 & $1(4)$ \\
\hline \multicolumn{5}{|l|}{ Age (years) } \\
\hline Mean (SD) & $57(12)$ & $60(11)$ & $58(12)$ & $58(11)$ \\
\hline \multicolumn{5}{|c|}{ Age group, n (\%) } \\
\hline$<50$ years & $4(36)$ & $5(22)$ & $3(33)$ & $5(19)$ \\
\hline $50-65$ years & $3(27)$ & $8(35)$ & $2(22)$ & $15(56)$ \\
\hline$\geq 65$ years & $4(36)$ & $10(43)$ & $4(44)$ & $7(26)$ \\
\hline \multicolumn{5}{|c|}{ Age at diagnosis (years) } \\
\hline Mean (SD) & $51(14)$ & $56(12)$ & $54(14)$ & $58(11)$ \\
\hline \multicolumn{5}{|c|}{ Estrogen receptor (ER) status } \\
\hline+ & $7(64)$ & $14(61)$ & $6(67)$ & $20(74)$ \\
\hline- & $3(27)$ & $9(39)$ & $3(33)$ & $7(26)$ \\
\hline Not done & $1(9)$ & 0 & 0 & 0 \\
\hline \multicolumn{5}{|c|}{ Progesterone receptor (PR) status } \\
\hline+ & $5(45)$ & $10(43)$ & $4(44)$ & $11(41)$ \\
\hline- & $5(45)$ & $13(57)$ & $5(56)$ & $16(59)$ \\
\hline Not done & $1(9)$ & 0 & 0 & 0 \\
\hline \multicolumn{5}{|c|}{ HER2 status, n (\%) } \\
\hline+ & $11(100)$ & $23(100)$ & $9(100)$ & $27(100)$ \\
\hline- & 0 & 0 & 0 & 0 \\
\hline
\end{tabular}

$S D$ standard deviation 


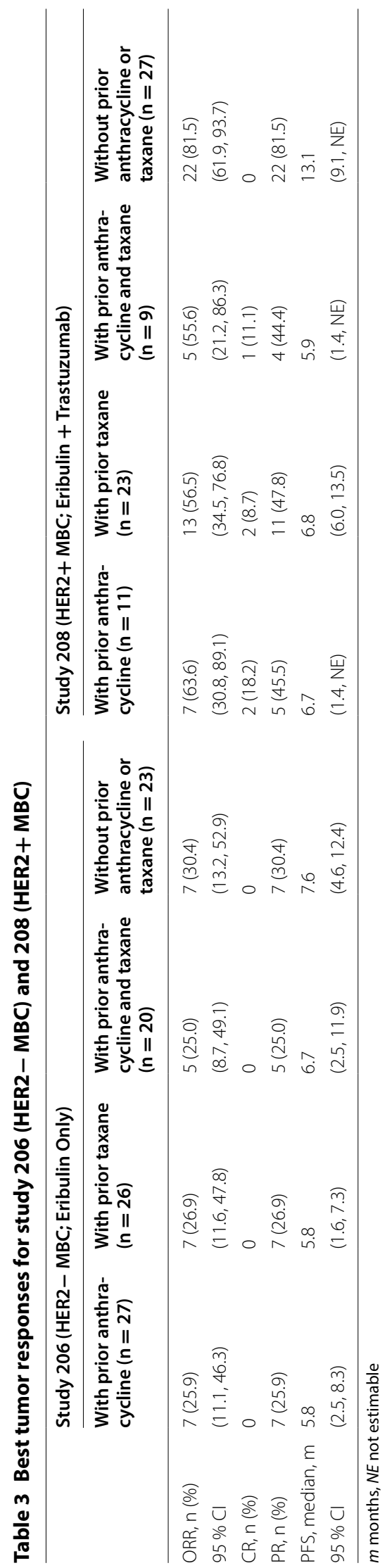



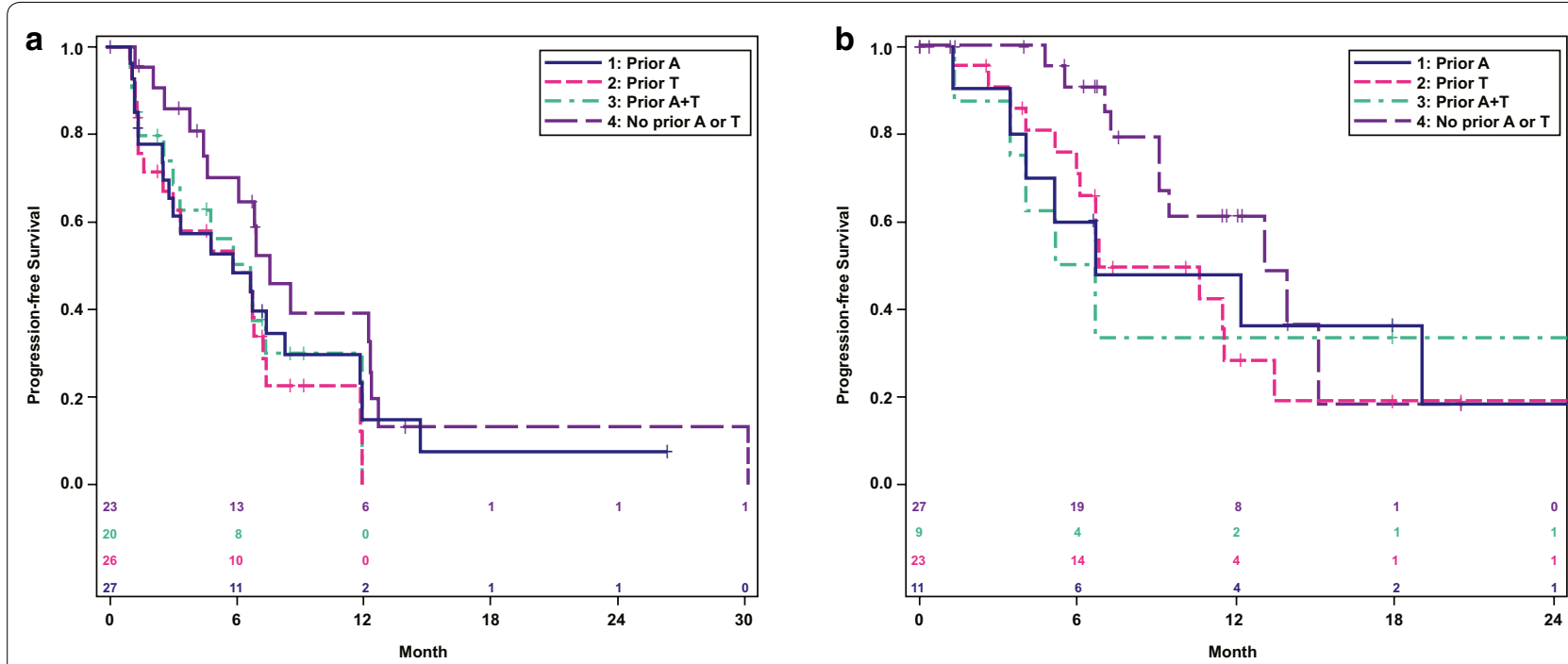

Fig. 1 a Study 206 (Single-Agent Eribulin): Kaplan-Meier plot of progression-free survival by prior anthracycline (A) and/or taxane (T) treatment. b Study 208 (Eribulin + Trastuzumab): Kaplan-Meier plot of progression-free survival by prior anthracycline (A) and/or taxane (T) treatment

anthracycline and taxane $(70.0 \%)$, but the rate was lower among patients who were anthracycline- and taxane-naïve (43.5 \%). In Study 208, dose modifications occurred at a similar rate in patients who had received prior anthracycline $(54.5 \%)$, prior taxane $(56.5 \%)$, or both anthracycline and taxane (55.6\%), and were slightly higher in patients who were anthracycline- and taxanenaïve (63.0\%).

Rates of peripheral neuropathy and neutropenia are summarized in Table 4. In Study 206, rates of grade 2 (15.4-20.0 \%) and grade 3 neuropathy (18.5-26.1\%) were generally similar, regardless of prior treatment (no grade $\geq 4$ neuropathy was reported). The rate of neutropenia was lower among patients who were anthracycline- and taxane-naive (56.5\%), and was relatively similar among the other three groups (77.8-84.6\%). In Study 208, patients who had received taxanes had higher rates of grade 2 neuropathy $(30.4 \%)$ relative to the other groups (14.8-22.2 \%), while those who were anthracycline- and taxane-naive had higher rates of grade 3 neuropathy (37.0\%) relative to the other groups (11.1-18.2 \%); no grade $\geq 4$ neuropathy was reported. The rate of neutropenia was higher among those who had received prior anthracyclines $(81.8 \%)$ and those who had received both prior anthracycline and taxane (77.8\%), somewhat lower among those who had received prior taxane $(65.2 \%)$, and lowest among those who were anthracycline- and taxanenaïve (51.9\%).

\section{Discussion}

First-line therapy for recurrent $\mathrm{BC}$ or $\mathrm{MBC}$ with eribulin (Study 206) or eribulin plus trastuzumab (Study 208) demonstrated antitumor activity with acceptable tolerability irrespective of prior anthracycline and/or taxane treatment. For Study 206, ORR was similar regardless of prior anthracycline and/or taxane treatment (ORR range: 25.0-30.4\%), although median PFS was slightly longer among patients who were both anthracycline- and taxane-naïve (7.6 months) relative to those who had received prior treatment (range 5.8-6.7 months). In Study 208, ORR was higher (81.5 \%) and median PFS (13.1 months) was longer in patients who had not received prior anthracycline or taxane treatment compared to those who had received prior anthracycline and/or taxane treatment (ORR range 55.6-63.6 \%; PFS range 5.9-6.8 months), suggesting that patients who are both anthracycline- and taxane-naïve have prolonged benefit from first-line eribulin plus trastuzumab.

Results for Study 206 presented here are comparable to those obtained with single-agent anthracyclines or taxanes. In a phase 3 study that compared doxorubicin and pegylated liposomal doxorubicin $(\mathrm{N}=509)$, ORRs were 38 and $33 \%$, respectively, with $25 \%$ of patients in each group having stable disease (SD), and a PFS of 7.8 and 6.9 months, respectively (O'Brien et al. 2004). In an analysis of individual patient data from studies using firstline single-agent anthracycline (doxorubicin) or taxane therapy (paclitaxel or docetaxel), ORRs were $38 \%$ with anthracyclines and $33 \%$ for taxanes $(P=0.08)$, and SD of 37 and $40 \%$, with a median PFS of 7.2 and 5.1 months, respectively (Piccart-Gebhart et al. 2008).

In Study 208, eribulin plus trastuzumab as first-line treatment for patients with HER2+ locally advanced BC or $\mathrm{MBC}$ demonstrated anti-tumor activity comparable to 


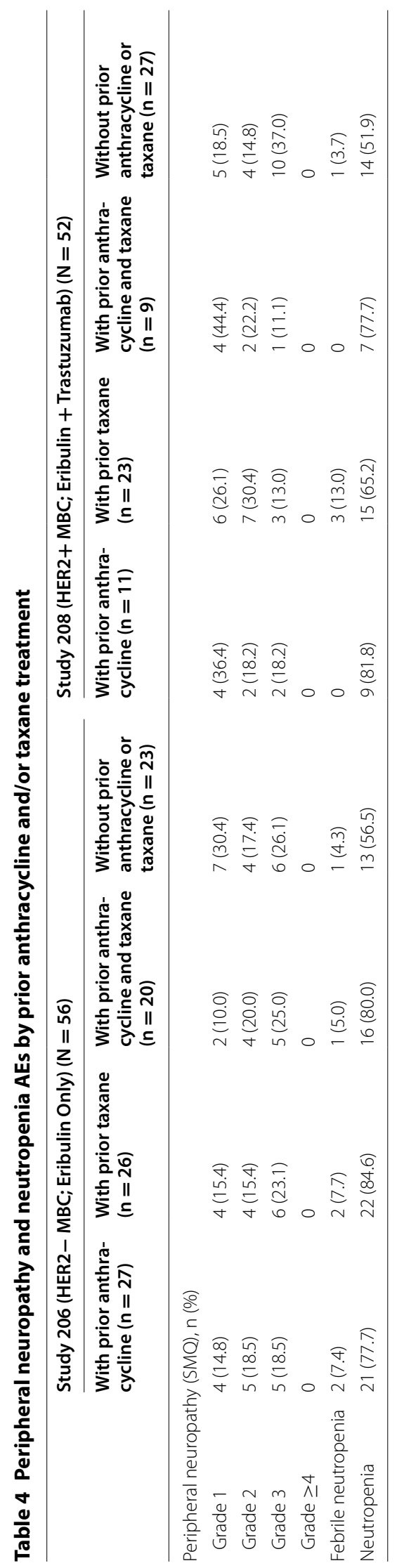


those reported for other chemotherapy combinations evaluated in this setting. Studies of trastuzumab plus docetaxel demonstrated ORRs ranging from 45 to $61 \%$ and PFS ranging from 8.3 to 12.4 months (Hurvitz et al. 2013; Servitja et al. 2012; Andersson et al. 2011; Marty et al. 2005). A study that compared vinorelbine plus trastuzumab vs docetaxel plus trastuzumab reported an ORR of $59.3 \%$ in both arms and time to progression of 15.3 and 12.4 months, respectively (Andersson et al. 2011). A study of combined oral or IV vinorelbine with trastuzumab reported an ORR of $70.3 \%$ and time to progression of 9.3 months (Heinemann et al. 2011). The combination of capecitabine plus trastuzumab has resulted in an ORR of $38-65 \%$ and PFS of 7.8 months (Yamamoto et al. 2008; Michalaki et al. 2010). ORRs from 36 to $75 \%$ and PFS ranging from 7.1 to 9.9 months were demonstrated in trials combining trastuzumab and paclitaxel (Fountzilas et al. 2001; Gasparini et al. 2007; Robert et al. 2006). For the combination of trastuzumab plus paclitaxel and carboplatin, a PFS of 10.7 months and an ORR of $52 \%$ was reported (Robert et al. 2006). However, with the large improvement in median OS observed with the addition of pertuzumab to docetaxel and trastuzumab as first-line treatment for HER2+ MBC (Baselga et al. 2012; Swain et al. 2013, 2014), the combination of trastuzumab plus pertuzumab and docetaxel (or paclitaxel) is recommended as the preferred standard of care (National Comprehensive Cancer Network 2015). The NCCN guidelines include trastuzumab alone or with docetaxel, vinorelbine, capecitabine, or paclitaxel; with or without carboplatin, as other first-line options (National Comprehensive Cancer Network 2015).

In both studies, tolerability was generally similar for chemotherapy-naïve patients and patients who had received prior anthracyclines and/or taxanes. In Study 206, the rate of serious TEAEs among chemotherapynaïve patients was similar to the rates among anthracycline-pretreated patients and taxane-pretreated patients, although the rate was lower among patients who had received both anthracycline and taxane treatment. In Study 208, rates of serious TEAEs were comparable for chemotherapy-naïve and patients with prior anthracycline and/or taxane treatment. In both studies, rates of neuropathy (any grade) were similar among the subgroups of patients who had received prior anthracycline and/or taxane treatment; the rate among chemotherapynaïve patients was greater than the rate among pretreated patients in Study 206 and was comparable to the rate among pretreated patients in Study 208. In both studies, rates of grade 2 and 3 neuropathy (no grade $\geq 4$ neuropathy was reported) among patients who had received prior taxane treatment were comparable to or less than the rates among chemotherapy-naïve patients.

\section{Conclusions}

As first-line therapy, eribulin in patients with HER2$M B C$ and eribulin plus trastuzumab in patients with HER2+ MBC was effective with acceptable tolerability, regardless of prior anthracycline or taxane treatment. In Study 206 (patients with HER2- MBC receiving eribulin only), ORRs and median PFS duration were similar in patients who had received prior anthracycline treatment and/or prior taxane therapy, although patients who were both anthracycline- and taxane-naïve had slightly longer median PFS. For Study 208 (patients with HER2+ MBC receiving combination eribulin/trastuzumab), ORR was higher and median PFS was longer among anthracycline- and taxane-naïve patients treated with eribulin plus trastuzumab compared with patients who had received prior anthracycline and/or taxane treatment. These data demonstrated that eribulin is an active agent in chemotherapy-naïve as well as in anthracycline- and/or taxane-pretreated patients with MBC.

\section{Additional file}

Additional file 1: Table S1. Eribulin Administration Throughout Study 206 and Study 208.

\section{Abbreviations}

AE: adverse event; BC: breast cancer; CR: complete response; DOR: duration of response; FAS: full analysis set; HER2: human epidermal growth factor receptor 2; HER2-: human epidermal growth factor receptor 2-negative; HER2+: human epidermal growth factor receptor 2-positive; MBC: metastatic breast cancer; ORR: objective response rate; OS: overall survival; PFS: progression-free survival; PR: partial response; SD: stable disease; TEAE: treatment-emergent adverse event.

\section{Authors' contributions}

JS participated in the design of the study and performed the statistical analysis. JO, LS, SW, SP, EB, JS, LV conceived of the study, and participated in its design and coordination and helped to draft the manuscript. All authors read and approved the final manuscript.

\section{Author details \\ ${ }^{1}$ Texas Oncology-Baylor Charles A. Sammons Cancer Center, US Oncology, 3410 Worth Street, Ste 400, Dallas, TX 75246, USA. ${ }^{2}$ Texas Oncology-Dallas Presbyterian Hospital, US Oncology, Dallas, TX 75231, USA. ${ }^{3}$ West Clinic, Mem- phis, TN 38120, USA. ${ }^{4}$ US Oncology-Cancer Care Centers of South Texas, San Antonio, TX 78217, USA. ${ }^{5}$ University of Pittsburgh Medical Center, Pittsburgh, PA 15213, USA. ${ }^{6}$ Eisai Inc., Woodcliff Lake, NJ 07677, USA. ${ }^{7}$ Weill Cornell Medi- cal College, New York, NY 10065, USA.}

\section{Acknowledgements}

The authors thank Leonard Lionnet, PhD and Sherri D. Jones, PharmD of MedVal Scientific Information Services, LLC, for providing medical writing and editorial assistance. This manuscript was prepared according to the International Society for Medical Publication Professionals'“Good Publication Practice for Communicating Company-Sponsored Medical Research: The GPP2 Guidelines." Funding to support this study and the preparation of this manuscript was provided by Eisai Inc. 


\section{Compliance with ethical guidelines}

\section{Competing interests}

Joyce O'Shaughnessy: Consultant for Eisai Inc. Kristi McIntyre and Sharon Wilks: None to report. Lee Schwartzberg: Consultant for and received research support from Eisai Inc. Shannon Puhalla: Consultant for Celldex, Medimmune, Pfizer. Erhan Berrak and James Song: Employee of Eisai Inc. Linda Vahdat: Consultant for and member of speakers bureau for Eisai Inc.

Received: 28 July 2015 Accepted: 8 September 2015 Published online: 21 September 2015

\section{References}

(2014) Halaven ${ }^{\circledR}$ (eribulin mesylate) injection (prescribing information). Eisai Inc., Woodcliff Lake

American Cancer Society (2014) Breast cancer facts and figures 2013-2014. http://www.cancer.org/acs/groups/content/@research/documents/ document/acspc-040951.pdf. Accessed 10 Feb 2014

Andersson M, Lidbrink E, Bjerre K, Wist E, Enevoldsen K, Jensen AB, Karlsson P, Tange UB, Sorensen PG, Moller S, Bergh J, Langkjer ST (2011) Phase III randomized study comparing docetaxel plus trastuzumab with vinorelbine plus trastuzumab as first-line therapy of metastatic or locally advanced human epidermal growth factor receptor 2-positive breast cancer: the HERNATA study. J Clin Oncol 29:264-271

Aogi K, Iwata H, Masuda N, Mukai H, Yoshida M, Rai Y, Taguchi K, Sasaki Y, Takashima S (2012) A phase II study of eribulin in Japanese patients with heavily pretreated metastatic breast cancer. Ann Oncol 23:1441-1448

Baselga J, Cortes J, Kim SB, Im SA, Hegg R, Im YH, Roman L, Pedrini JL, Pienkowski T, Knott A, Clark E, Benyunes MC, Ross G, Swain SM (2012) Pertuzumab plus trastuzumab plus docetaxel for metastatic breast cancer. $\mathrm{N}$ Engl J Med 366:109-119

Cortes J, O'Shaughnessy J, Loesch D, Blum JL, Vahdat LT, Petrakova K, Chollet P, Manikas A, Dieras V, Delozier T, Vladimirov V, Cardoso F, Koh H, Bougnoux P, Dutcus CE, Seegobin S, Mir D, Meneses N, Wanders J, Twelves C (2011) Eribulin monotherapy versus treatment of physician's choice in patients with metastatic breast cancer (EMBRACE): a phase 3 open-label randomised study. Lancet 377:914-923

Cortes J, Vahdat L, Blum JL, Twelves C, Campone M, Roche H, Bachelot T, Awada A, Paridaens R, Goncalves A, Shuster DE, Wanders J, Fang F, Gurnani R, Richmond E, Cole PE, Ashworth S, Allison MA (2010) Phase II study of the halichondrin B analog eribulin mesylate in patients with locally advanced or metastatic breast cancer previously treated with an anthracycline, a taxane, and capecitabine. J Clin Oncol 28:3922-3928

Fountzilas G, Tsavdaridis D, Kalogera-Fountzila A, Christodoulou CH, Timotheadou E, Kalofonos CH, Kosmidis P, Adamou A, Papakostas P, Gogas H, Stathopoulos G, Razis E, Bafaloukos D, Skarlos D (2001) Weekly paclitaxel as first-line chemotherapy and trastuzumab in patients with advanced breast cancer. A Hellenic Cooperative Oncology Group phase II study. Ann Oncol 12:1545-1551

Gasparini G, Gion M, Mariani L, Papaldo P, Crivellari D, Filippelli G, Morabito A, Silingardi V, Torino F, Spada A, Zancan M, De Sio L, Caputo A, Cognetti F, Lambiase A, Amadori D (2007) Randomized Phase II Trial of weekly paclitaxel alone versus trastuzumab plus weekly paclitaxel as first-line therapy of patients with Her-2 positive advanced breast cancer. Breast Cancer Res Treat 101:355-365

Giordano SH, Temin S, Kirshner JJ, Chandarlapaty S, Crews JR, Davidson NE, Esteva FJ, Gonzalez-Angulo AM, Krop I, Levinson J, Lin NU, Modi S, Patt DA, Perez EA, Perlmutter J, Ramakrishna N, Winer EP (2014) Systemic therapy for patients with advanced human epidermal growth factor receptor 2-positive breast cancer: American Society of Clinical Oncology clinical practice guideline. J Clin Oncol 32:2078-2099

Heinemann V, Di Gioia D, Vehling-Kaiser U, Harich HD, Heinrich B, Welt A, Ziske C, Deutsch G, Pihusch R, Kolbl H, Hegewisch-Becker S, Michl M, Stemmler HJ (2011) A prospective multicenter phase II study of oral and i.v. vinorelbine plus trastuzumab as first-line therapy in HER2-overexpressing metastatic breast cancer. Ann Oncol 22:603-608

Hurvitz SA, Dirix L, Kocsis J, Bianchi GV, Lu J, Vinholes J, Guardino E, Song C, Tong B, Ng V, Chu YW, Perez EA (2013) Phase II randomized study of trastuzumab emtansine versus trastuzumab plus docetaxel in patients with human epidermal growth factor receptor 2-positive metastatic breast cancer. J Clin Oncol 31:1157-1163

Jain S, Cigler T (2012) Eribulin mesylate in the treatment of metastatic breast cancer. Biologics 6:21-29

Jordan MA, Kamath K (2007) How do microtubule-targeted drugs work? An overview. Curr Cancer Drug Targets 7:730-742

Jordan MA, Kamath K, Manna T, Okouneva T, Miller HP, Davis C, Littlefield BA, Wilson $L$ (2005) The primary antimitotic mechanism of action of the synthetic halichondrin E7389 is suppression of microtubule growth. Mol Cancer Ther 4:1086-1095

Kaufman PA, Awada A, Twelves C, Yelle L, Perez EA, Velikova G, Olivo MS, He Y, Dutcus CE, Cortes J (2015) Phase III open-label randomized study of eribulin mesylate versus capecitabine in patients with locally advanced or metastatic breast cancer previously treated with an anthracycline and a taxane. J Clin Oncol 33:594-601

Marty M, Cognetti F, Maraninchi D, Snyder R, Mauriac L, Tubiana-Hulin M, Chan S, Grimes D, Anton A, Lluch A, Kennedy J, O'Byrne K, Conte P, Green M, Ward C, Mayne K, Extra JM (2005) Randomized phase II trial of the efficacy and safety of trastuzumab combined with docetaxel in patients with human epidermal growth factor receptor 2-positive metastatic breast cancer administered as first-line treatment: the M77001 study group. J Clin Oncol 23:4265-4274

Mclntyre K, O'Shaughnessy J, Schwartzberg L, Gluck S, Berrak E, Song JX, Cox D, Vahdat LT (2014) Phase 2 study of eribulin mesylate as first-line therapy for locally recurrent or metastatic human epidermal growth factor receptor 2-negative breast cancer. Breast Cancer Res Treat 146:321-328

Michalaki V, Fotiou S, Gennatas S, Gennatas C (2010) Trastuzumab plus capecitabine and docetaxel as first-line therapy for HER2-positive metastatic breast cancer: phase II results. Anticancer Res 30:3051-3054

National Comprehensive Cancer Network (2015) NCCN Clinical Practice Guidelines in Oncology (NCCN Guidelines) ${ }^{\circledR}$ : Breast Cancer Version 2.2015. National Comprehensive Cancer Network, Fort Washington. Accessed 11 Mar 2015

National Cancer Institute (2014) SEER Stat fact sheets: breast. http://seer. cancer.gov/statfacts/html/breast.html. Accessed 14 Jan 2014

Okouneva T, Azarenko O, Wilson L, Littlefield BA, Jordan MA (2008) Inhibition of centromere dynamics by eribulin (E7389) during mitotic metaphase. Mol Cancer Ther 7:2003-2011

O'Brien MER, Wigler N, Inbar M, Rosso R, Grischke E, Santoro A, Catane R, Kieback DG, Tomczak P, Ackland SP, Orlandi F, Mellars L, Alland L, Tendler C (2004) Reduced cardiotoxicity and comparable efficacy in a phase III trial of pegylated liposomal doxorubicin $\mathrm{HCl}\left(\mathrm{CAELYX} \mathrm{X}^{\mathrm{TM}} /\right.$ Doxil $\left.{ }^{\circledR}\right)$ versus conventional doxorubicin for first-line treatment of metastatic breast cancer. Ann Oncol 15:440-449

O'Shaughnessy J (2005) Extending survival with chemotherapy in metastatic breast cancer. Oncologist 10(Suppl 3):20-29

Partridge AH, Rumble RB, Carey LA, Come SE, Davidson NE, Di Leo A, Gralow J, Hortobagyi GN, Moy B, Yee D, Brundage SB, Danso MA, Wilcox M, Smith IE (2014) Chemotherapy and targeted therapy for women with human epidermal growth factor receptor 2-negative (or unknown) advanced breast cancer: American Society of Clinical Oncology Clinical Practice Guideline. J Clin Oncol 32:3307-3329

Piccart-Gebhart MJ, Burzykowski T, Buyse M, Sledge G, Carmichael J, Luck HJ, Mackey JR, Nabholtz JM, Paridaens R, Biganzoli L, Jassem J, Bontenbal M, Bonneterre J, Chan S, Basaran GA, Therasse P (2008) Taxanes alone or in combination with anthracyclines as first-line therapy of patients with metastatic breast cancer. J Clin Oncol 26:1980-1986

Robert N, Leyland-Jones B, Asmar L, Belt R, llegbodu D, Loesch D, Raju R, Valentine E, Sayre R, Cobleigh M, Albain K, McCullough C, Fuchs L, Slamon D (2006) Randomized phase III study of trastuzumab, paclitaxel, and carboplatin compared with trastuzumab and paclitaxel in women with HER2-overexpressing metastatic breast cancer. J Clin Oncol 24:2786-2792

Ross JS, Slodkowska EA, Symmans WF, Pusztai L, Ravdin PM, Hortobagyi GN (2009) The HER-2 receptor and breast cancer: ten years of targeted antiHER-2 therapy and personalized medicine. Oncologist 14:320-368

Servitja S, Ramos M, Gil M, Sanchez-Rovira P, Vazquez-Estevez S, Virizuela JA, Garcia-Estevez L, Velasco A, Tusquets I (2012) Multicenter, phase II, nonrandomized study of docetaxel plus trastuzumab every 21 days as the primary therapy in metastatic breast cancer overexpressing HER2. Anticancer Drugs 23:239-246 
Smith JA, Wilson L, Azarenko O, Zhu X, Lewis BM, Littlefield BA, Jordan MA (2010) Eribulin binds at microtubule ends to a single site on tubulin to suppress dynamic instability. Biochemistry 49:1331-1337

Swain SM, Kim SB, Cortes J, Ro J, Semiglazov V, Campone M, Ciruelos E, Ferrero JM, Schneeweiss A, Knott A, Clark E, Ross G, Benyunes MC, Baselga J (2013) Pertuzumab, trastuzumab, and docetaxel for HER2-positive metastatic breast cancer (CLEOPATRA study): overall survival results from a randomised, double-blind, placebo-controlled, phase 3 study. Lancet Oncol 14:461-471

Swain S, Kim S, Cortes J et al (2014) Final overall survival (OS) analysis from the CLEOPATRA study of first-line (1L) pertuzumab (Ptz), trastuzumab $(\mathrm{T})$, and docetaxel (D) in patients (pts) with HER2-positive metastatic breast cancer (MBC). In: Annual Congress of the European Society for Medical Oncology, September 26-30, 2014, Madrid, Spain

Vahdat LT, Pruitt B, Fabian CJ, Rivera RR, Smith DA, Tan-Chiu E, Wright J, Tan AR, Dacosta NA, Chuang E, Smith J, O'Shaughnessy J, Shuster DE, Meneses NL, Chandrawansa K, Fang F, Cole PE, Ashworth S, Blum JL (2009) Phase II study of eribulin mesylate, a halichondrin B analog, in patients with metastatic breast cancer previously treated with an anthracycline and a taxane. J Clin Oncol 27:2954-2961

Valabrega G, Montemurro F, Aglietta M (2007) Trastuzumab: mechanism of action, resistance and future perspectives in HER2-overexpressing breast cancer. Ann Oncol 18:977-984

Wilks S, Puhalla S, O'Shaughnessy J, Schwartzberg L, Berrak E, Song J, Cox D, Vahdat L (2014) Phase 2, multicenter, single-arm study of eribulin mesylate plus trastuzumab as first-line therapy for locally recurrent or metastatic HER2-positive breast cancer. Clin Breast Cancer 14:405-412

Yamamoto D, Iwase S, Kitamura K, Odagiri H, Yamamoto C, Nagumo Y (2008) A phase II study of trastuzumab and capecitabine for patients with HER2overexpressing metastatic breast cancer: Japan Breast Cancer Research Network (JBCRN) 00 Trial. Cancer Chemother Pharmacol 61:509-514

\section{Submit your manuscript to a SpringerOpen ${ }^{\odot}$ journal and benefit from:}

- Convenient online submission

- Rigorous peer review

- Immediate publication on acceptance

- Open access: articles freely available online

- High visibility within the field

- Retaining the copyright to your article

Submit your next manuscript at $>$ springeropen.com 